\title{
Assessment of bronchodilatation after spontaneous recovery from a histamine challenge in asthmatic children
}

\author{
P J F M Merkus, H M Eelkman Rooda, E E M van Essen-Zandvliet, E J Duiverman, \\ Ph H Quanjer, K F Kerrebijn
}

\begin{abstract}
Background It would be convenient to be able to measure airway responsiveness to histamine and to bronchodilator drugs on the same day, but whether this can be done reliably is unknown.

Methods The effect of a prior histamine challenge on the bronchodilator response to salbutamol after spontaneous recovery of $\mathrm{FEV}_{1}$ to $95 \%$ of the prechallenge level was studied in two groups of asthmatic children. Fourteen children inhaled $400 \mu \mathrm{g}$ salbutamol after spontaneous recovery from a histamine challenge, followed by a further $100 \mu \mathrm{g}$ salbutamol 20 minutes later. In a second group of eight asthmatic children the study was repeated with $800 \mu \mathrm{g}$ salbutamol, followed by a further $200 \mu \mathrm{g} 20$ minutes later.
\end{abstract}

Results After histamine challenge $\mathrm{FEV}_{1}$ returned to baseline in 70 minutes or less on all occasions. The FEV, 20 minutes after $\mathbf{4 0 0} \mu \mathrm{g}$ salbutamol was significantly lower after the histamine challenge than on the control day. After the further $100 \mu \mathrm{g}$ salbutamol $\mathrm{FEV}_{1}$ values were similar after the histamine challenge and on the control day. FEV values after $800 \mu \mathrm{g}$ salbutamol and the further $200 \mu \mathrm{g}$ dose were not influenced by a prior histamine challenge.

Conclusions In children with stable asthma in whom $F_{1} V_{1}$ has returned to baseline after a histamine challenge the $\mathrm{FEV}_{1}$ achieved after $800 \mu \mathrm{g}$ salbutamol is not affected by the histamine challenge. Histamine and bronchodilator responsiveness can thus be assessed reliably on the same day in patients with stable asthma. This has clear advantages for patient care.

Airway responsiveness to $\beta_{2}$ sympathomimetic drugs and to histamine or methacholine are often considered as indicators of asthma severity when asthma is stable. Both tests have an important role in the clinical assessment of asthma and in research ${ }^{1}$; it would be convenient if they could be carried out on the same day.

Combining a bronchodilator and a bronchoconstrictor test on the same day might, however, produce unreliable findings. There is ample evidence that $\beta_{2}$ agonists protect against histamine induced bronchoconstriction for several hours. ${ }^{2}$ The effect of a histamine challenge on histamine responsiveness has also been investigated, ${ }^{34}$ but little is known about the effect of acute histamine induced bronchoconstriction on a subsequent bronchodilator test.

A histamine challenge may affect the response to a $\beta_{2}$ agonist even after airway calibre has returned to baseline. Histamine is metabolised within minutes ${ }^{5}$ and does not accumulate, provided that several minutes are allowed between inhalations ${ }^{6}$; histamine, however, may reduce air flow for longer. ${ }^{7}$ The forced expiratory volume in one second $\left(\mathrm{FEV}_{1}\right)$ recovers within 60 minutes of histamine administration, ${ }^{8}$ the recovery time being positively correlated with the dose of inhaled histamine and the magnitude of the response. $^{89}$ Thus some of the bronchoconstriction is not short lived. The mechanisms of recovery from a histamine challenge are poorly understood.

The purpose of this study was to investigate the effect of a prior histamine challenge on bronchodilatation with salbutamol after spontaneous recovery of $\mathrm{FEV}_{1}$ to the baseline level, to assess whether the two tests can be performed reliably on the same day.

\section{Methods}

PATIENTS

Subjects were selected from the outpatient clinics for respiratory medicine of the Juliana and Sophia Children's Hospitals in The Hague and Rotterdam. Criteria for inclusion were: (1) asthma that was stable for three weeks before the study; (2) baseline values of $\mathrm{FEV}_{1}$ of $50-90 \%$ of predicted or an $\mathrm{FEV}_{1}$ / FVC of $60-75 \%$, or both; (3) dose of histamine that reduced $\mathrm{FEV}_{1}$ by $20 \%\left(\mathrm{PD}_{20}\right)$ less than $150 \mu \mathrm{g}$; (4) ability to perform forced expiratory manoeuvres reproducibly; (5) age 7-14 years. All medication was discontinued before the tests (eight hours in advance for inhaled drugs and 48 hours for oral drugs). The study was carried out with the informed consent of both children and parents, and was approved by the local medical ethics committee.

BRONCHODILATOR RESPONSE AND BRONCHIAL HYPERRESPONSIVENESS

FEV , was measured with a rolling seal spirometer (Vicatest 5, 10 litre volume displacement) with a resolution of $20 \mathrm{ml}$, connected to a computer. The spirometer was heated 
to $35 \cdot 5^{\circ} \mathrm{C}$; volumes were corrected to BTPS. The best of three technically satisfactory $\mathrm{FEV}_{1}$ measurements was recorded ${ }^{10}$ and expressed as percentage of the predicted value. ${ }^{11}$

Bronchodilation was assessed from two sequential inhalations of salbutamol at 20 minute intervals. A two step administration of salbutamol was preferred to a single administration because it might result in a greater increase in $\mathrm{FEV}_{1}$, as a result of better penetration of the second dose when some bronchodilation has been achieved. ${ }^{12}$ Salbutamol was administered from a metered dose inhaler with a spacer (Volumatic), the dose depending on the protocol: puffs contained $100 \mu \mathrm{g}$ (protocol 1) or $200 \mu \mathrm{g}$ salbutamol (protocol 2). Salbutamol was inhaled during a single slow inspiration from functional residual capacity to total lung capacity immediately after each actuation. The breath was then held for about 10 seconds before exhalation. This was done on four occasions and $\mathrm{FEV}_{1}$ was recorded 20 minutes after each dose of salbutamol. One more puff was then inhaled in the same fashion and $\mathrm{FEV}_{1}$ was again measured 20 minutes later.

Aerosolised histamine diphosphate was inhaled from a calibrated DeVilbiss 646 nebuliser with its vent closed and primed with $3 \mathrm{ml}$ solution. The nebuliser was attached to a Rosenthal-French dosimeter driven by air at $137.8 \mathrm{kPa}\left(20 \mathrm{lb} / \mathrm{in}^{2}\right)$. The aerosol was delivered directly into the mouth through a mouth tube. The subject inspired as slowly as possible from functional residual capacity to total lung capacity. During the inspiration the dosimeter was triggered for 0.6 seconds. At the end of the inspiration the children were asked to hold their breath for about two seconds. With this technique lung deposition should be maximal. ${ }^{13} \mathrm{~A}$ total of $20 \mu \mathrm{l}$ of histamine solution was delivered to the mouth in four consecutive breaths. Histamine diphosphate in buffered saline was given in doubling concentrations $(0 \cdot 25-32 \mathrm{mg} / \mathrm{ml}) . \mathrm{PD}_{20}$ was calculated by interpolation of the dose-response curve on a log-linear scale. ${ }^{14}$

\section{STUDY PROTOCOLS}

Protocol 1

Children were investigated in a randomised crossover design at about the same time of the day on two days within two weeks. On the control day a baseline measurement of $\mathrm{FEV}_{1}$ was followed by four inhalations of $100 \mu \mathrm{g}$ salbutamol and a further measurement of $\mathrm{FEV}_{1} 20$ minutes later. A further $100 \mu \mathrm{g}$ salbutamol was then administered and FEV measured again after 20 minutes. On the histamine challenge day baseline measurement of $\mathrm{FEV}_{1}$ (baseline 1) was followed by a histamine challenge test until FEV fell by $20 \%$. FEV $_{1}$ was then allowed to recover spontaneously. Recovery was monitored 60 and 70 minutes after the end of the histamine challenge. It was regarded as complete when $\mathrm{FEV}_{1}$ had returned to at least $95 \%$ of baseline 1 in 70 minutes (baseline 2). Seventy minutes after the histamine challenge the two step broncho- dilatation was measured as on the control day. Subjects were excluded when complete recovery was not achieved, or when the baseline $\mathrm{FEV}_{1}$ measurement on the first day differed more than $10 \%$ from that on the second day.

\section{Protocol 2}

The design was the same as in protocol 1 , except that twice as much salbutamol was administered, puffs of $200 \mu \mathrm{g}$ each being used. Four inhalations of $200 \mu \mathrm{g}$ salbutamol were administered, followed by one inhalation of $200 \mu \mathrm{g}$ salbutamol 20 minutes later.

\section{DATA ANAL YSIS}

The hypothesis tested was that change in $\mathrm{FEV}_{1}$ after a given dose of salbutamol would be the same with as without a prior histamine challenge. Post-bronchodilator FEV $\%$ predicted and increase in $\mathrm{FEV}_{1} \%$ predicted were analysed by means of two tailed paired $t$ tests, with the level of significance set at $p=$ 0.05 . Differences were reported as means with $95 \%$ confidence limits (CL). A significant difference in post-bronchodilator $\mathrm{FEV}_{1}$ was defined as a difference greater than the standard deviation of the reproducibility of FEV $\%$ predicted before bronchodilatation in asthmatic children. In 78 children with stable asthma this was $3.52 \%$ predicted, and independent of the level of $\mathrm{FEV}_{1} \%$ predicted, age, and sex (own observations). From this it can be calculated that 12 subjects would be required to detect a difference in post-bronchodilator $\mathrm{FEV}_{1}$ of $4 \%$ predicted (the 75 th percentile of this reproducibility) with a power of $80 \%$.

\section{Results}

\section{PROTOCOL 1}

Of the 19 children who took part in the study, five failed to complete it, three for personal reasons and two because $\mathrm{FEV}_{1}$ recordings on the second day differed by more than $10 \%$ from those on the first day. Nine boys and five girls (age range $8 \cdot 1-13.5$ years) completed protocol 1 (table 1). FEV , had returned to baseline values in 11 children within 60 minutes, and in all after 70 minutes. There were no significant differences between baseline 1 and 2 FEV values before and after histamine (mean difference $-0 \cdot 2 \%$ predicted, $95 \% \mathrm{CL}-2 \cdot 5,2 \cdot 2)$, or between baseline on the control day and baseline 1 on the histamine challenge day (mean difference $0.5 \%$ predicted, $95 \%$ CL $-1 \cdot 1,2 \cdot 2)$ or baseline 2 on the histamine challenge day (mean difference $0.4 \%$ predicted, $95 \% \mathrm{CL}-2 \cdot 0,2 \cdot 8$ ).

Twenty minutes after administration of $400 \mu \mathrm{g}$ salbutamol $\mathrm{FEV}_{1}$ was significantly smaller on the histamine challenge day than on the control day (mean difference $-4.2 \%$ predicted, $95 \% \mathrm{CL}-7.4,-0.9 ; \mathrm{p}=0.016$ ) After a further $100 \mu \mathrm{g}$ salbutamol $\mathrm{FEV}_{1}$ did not differ from that on the control day (mean difference $-0.7 \%$ predicted, $95 \% \mathrm{CL}-3.4$, 2.0); fig 1). Change in $\mathrm{FEV}_{1} \%$ predicted after $400 \mu \mathrm{g}$ salbutamol on the control day was 
Table 1 Effects of previous histamine challenge on bronchodilator response assessed by $F E V_{1}$ : protocol 1

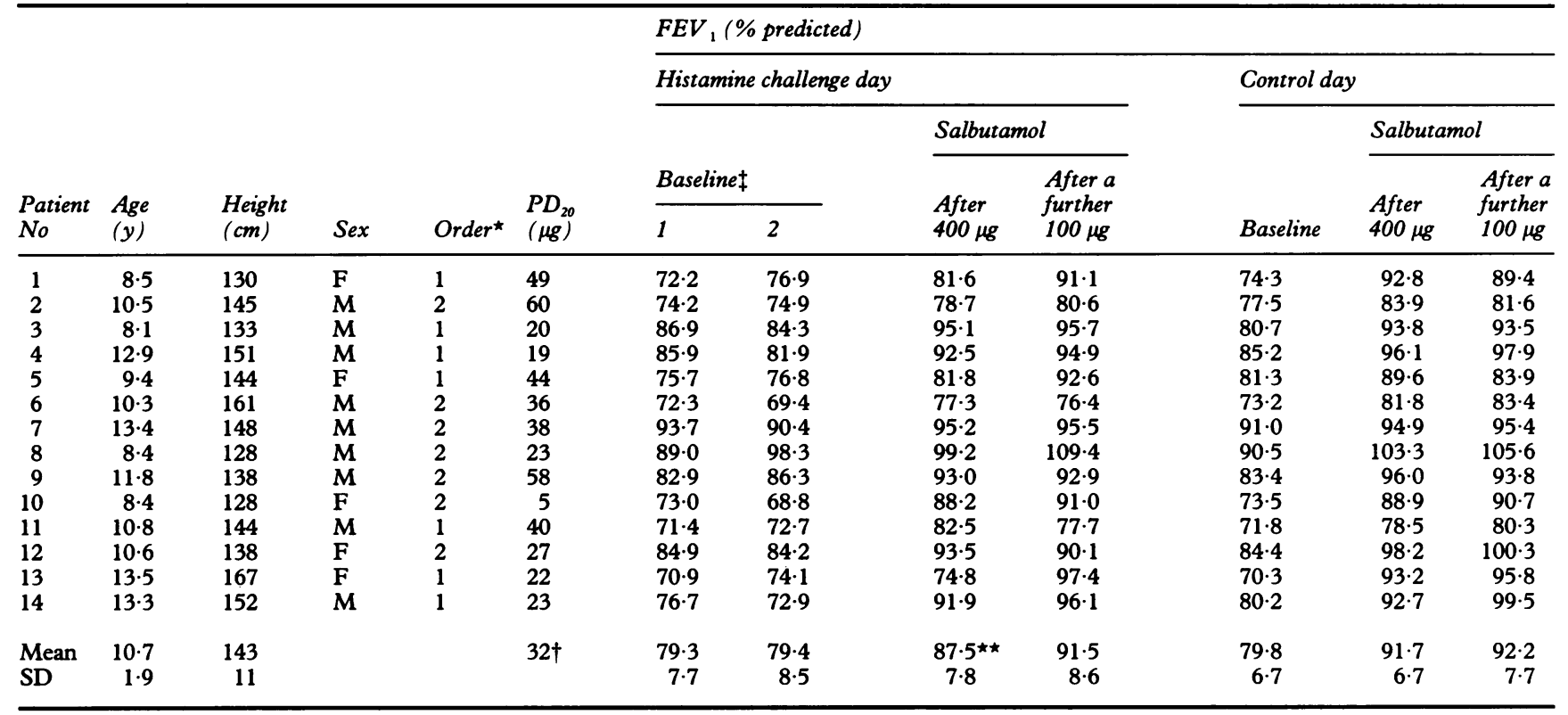

* 1 -Starting with histamine challenge test; 2 -starting with control experiments.

†Geometric mean. $\ddagger$ Baseline 1 -before histamine challenge; baseline $2-70$ minutes after histamine challenge.

$\star \star$ Significantly different from the control day after inhalation of $400 \mu \mathrm{g}$ salbutamol (p $<0.02$, Student's $t$ test).

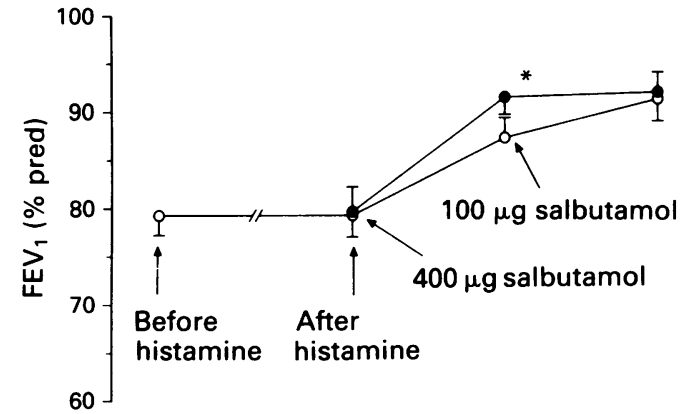

(Baseline 1) (Baseline 2)

Time (min)

Figure 1 Mean (SE) FEV (\% predicted) from protocol $1(n=14)$. Data refer to the control day (closed symbols) and the histamine challenge day (open symbols). ${ }^{\star} p=0.02$. significantly greater than on the histamine challenge when this was related to baseline 1 or pre-histamine $\mathrm{FEV}_{1}$ (mean difference 3.6\% predicted, $95 \%$ CL $0.4,6.8$ ) but not when this was related to baseline 2 or post-histamine $\mathrm{FEV}_{1}$ (mean difference $3.1 \%$ predicted, $95 \%$ CL $-0 \cdot 7,8 \cdot 2)$. The difference is because in one subject (No 8), whose $\mathrm{FEV}_{1}$ after recovery from histamine was $10 \%$ predicted higher than that before histamine. Change in $\mathrm{FEV}_{1}$ after the final $100 \mu \mathrm{g}$ salbutamol was similar on the two days (mean difference $-0.4 \%$ predicted, $95 \% \mathrm{CL}$ $-3 \cdot 8,3 \cdot 0)$.

\section{PROTOCOL 2}

Of the 10 participants, two boys were excluded because baseline 1 values for $\mathrm{FEV}_{1}$ on the second day differed by more than $10 \%$ from those on the first day; six boys and two girls completed protocol 2 (table 2 ). There were no

Table 2 Effects of previous histamine challenge on bronchodilator response assessed by $F E V_{1}$ : protocol 2

\begin{tabular}{|c|c|c|c|c|c|c|c|c|c|c|c|c|}
\hline \multirow{5}{*}{$\begin{array}{l}\text { Patient } \\
\text { No }\end{array}$} & \multirow{5}{*}{$\begin{array}{l}\text { Age } \\
(y)\end{array}$} & \multirow{5}{*}{$\begin{array}{l}\text { Height } \\
(\mathrm{cm})\end{array}$} & \multirow[b]{5}{*}{ Sex } & \multirow[b]{5}{*}{ Order ${ }^{\star}$} & \multirow{5}{*}{$\begin{array}{l}P D_{20} \\
(\mu g)\end{array}$} & \multicolumn{7}{|c|}{$F E V_{1}(\%$ predicted $)$} \\
\hline & & & & & & \multicolumn{4}{|c|}{ Histamine challenge day } & \multicolumn{3}{|c|}{ Control day } \\
\hline & & & & & & & & Salbuta & & \multirow[b]{3}{*}{ Baseline } & \multicolumn{2}{|c|}{ Salbutamol } \\
\hline & & & & & & \multicolumn{2}{|c|}{ Baseline } & \multirow{2}{*}{$\begin{array}{l}\text { After } \\
800 \mu \mathrm{g}\end{array}$} & \multirow{2}{*}{$\begin{array}{l}\text { After a } \\
\text { further } \\
200 \mu g\end{array}$} & & & After a \\
\hline & & & & & & 1 & 2 & & & & $800 \mu g$ & $200 \mu g$ \\
\hline $\begin{array}{l}1 \\
2 \\
3 \\
4 \\
5 \\
5 \\
6 \\
7 \\
8\end{array}$ & \begin{tabular}{r|}
$7 \cdot 1$ \\
$8 \cdot 4$ \\
$14 \cdot 3$ \\
$10 \cdot 3$ \\
$11 \cdot 8$ \\
$12 \cdot 9$ \\
$13 \cdot 5$ \\
$11 \cdot 8$
\end{tabular} & $\begin{array}{l}128 \\
126 \\
170 \\
145 \\
159 \\
157 \\
167 \\
154\end{array}$ & $\begin{array}{l}\mathbf{M} \\
\mathbf{M} \\
\mathbf{M} \\
\mathbf{F} \\
\mathbf{M} \\
\mathbf{M} \\
\mathbf{F} \\
\mathbf{M}\end{array}$ & $\begin{array}{l}1 \\
1 \\
1 \\
2 \\
1 \\
2 \\
1 \\
1\end{array}$ & $\begin{array}{r}18 \\
45 \\
3 \\
16 \\
14 \\
9 \\
4 \\
4\end{array}$ & $\begin{array}{l}81 \cdot 8 \\
75 \cdot 5 \\
53 \cdot 0 \\
85 \cdot 7 \\
78 \cdot 9 \\
59 \cdot 8 \\
62 \cdot 9 \\
62 \cdot 9\end{array}$ & $\begin{array}{l}77 \cdot 8 \\
73 \cdot 0 \\
50 \cdot 4 \\
83 \cdot 5 \\
74 \cdot 3 \\
60 \cdot 1 \\
65 \cdot 5 \\
65 \cdot 5\end{array}$ & $\begin{array}{r}95 \cdot 5 \\
82 \cdot 1 \\
81 \cdot 9 \\
102 \cdot 7 \\
104 \cdot 6 \\
79 \cdot 9 \\
91 \cdot 3 \\
91 \cdot 3\end{array}$ & $\begin{array}{r}93 \cdot 8 \\
85 \cdot 4 \\
81 \cdot 9 \\
102 \cdot 1 \\
110 \cdot 4 \\
84 \cdot 7 \\
92 \cdot 3 \\
92 \cdot 3\end{array}$ & $\begin{array}{l}85 \cdot 5 \\
79 \cdot 0 \\
48 \cdot 6 \\
75 \cdot 8 \\
79 \cdot 6 \\
55 \cdot 2 \\
67 \cdot 7 \\
63 \cdot 8\end{array}$ & $\begin{array}{r}93 \cdot 1 \\
88 \cdot 4 \\
72 \cdot 1 \\
101 \cdot 9 \\
102 \cdot 0 \\
75 \cdot 8 \\
90 \cdot 6 \\
93 \cdot 1\end{array}$ & $\begin{array}{r}93.2 \\
85.7 \\
75.9 \\
104.0 \\
107.4 \\
80.5 \\
93.6 \\
97.0\end{array}$ \\
\hline $\begin{array}{l}\text { Mean } \\
\text { SD }\end{array}$ & $\begin{array}{r}11 \cdot 3 \\
2.5\end{array}$ & $\begin{array}{l}151 \\
17 \cdot 0\end{array}$ & & & $12 \dagger$ & $\begin{array}{l}70 \cdot 8 \\
11 \cdot 6\end{array}$ & $\begin{array}{l}69 \cdot 8 \\
10 \cdot 6\end{array}$ & $\begin{array}{r}91 \cdot 1 \\
9 \cdot 6\end{array}$ & $\begin{array}{r}93.4 \\
9.6\end{array}$ & $\begin{array}{l}69.4 \\
12.9\end{array}$ & $\begin{array}{l}89.6 \\
10.9\end{array}$ & $\begin{array}{l}92 \cdot 2 \\
11 \cdot 0\end{array}$ \\
\hline
\end{tabular}

^1-Starting with histamine challenge test; 2 -starting with control experiments.

†Geometric mean. $\ddagger$ Baseline 1 - before histamine challenge; baseline $2-70$ minutes after histamine challenge. 
Figure 2 Mean (SE)

$F E V_{1}(\%$ predicted) from protocol $2(n=8)$. Data refer to the control day (closed symbols) and the histamine challenge day (open symbols).

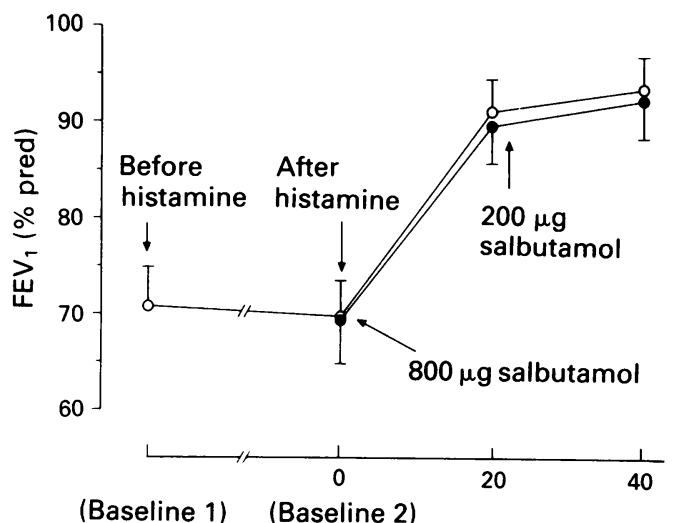

Time (min)

significant differences between baseline 1 and 2 before and after histamine (mean difference 1.0 $\%$ predicted, $95 \% \mathrm{CL}-1 \cdot 7,3 \cdot 8)$ or between baseline on the control day and baseline 1 on the histamine challenge day (mean difference $-1.4 \%$ predicted, $95 \% \mathrm{CL}-5.3,2.4)$ or baseline 2 on the histamine challenge day (mean difference $-0.4 \%$ predicted, $95 \% \mathrm{CL}$ $-5 \cdot 3,4 \cdot 6) . \mathrm{FEV}_{1}$ recovered spontaneously within 70 minutes in all children. Administration of $800 \mu \mathrm{g}$ salbutamol on the histamine challenge day resulted in an $\mathrm{FEV}_{1}$ value similar (fig 2) to that on the control day (mean difference $-2.0 \%$ predicted, $95 \%$ CL $-5.9,1.9)$, with little additional response to the final $200 \mu \mathrm{g}$ salbutamol (mean difference $-1.2 \%$ predicted, $95 \% \mathrm{CL}-4 \cdot 1,1 \cdot 7)$. Changes in $\mathrm{FEV}_{1}$ on the two days were similar, none of the differences reaching statistical significance.

\section{Discussion}

This is the first report to address the influence of a histamine provocation test on bronchodilatation after spontaneous recovery from such a challenge. It has been suggested that pulmonary function tests, such as assessment of bronchodilatation, can be performed after a histamine challenge when $\mathrm{FEV}_{1}$ has returned to $95 \%$ of baseline value. ${ }^{8} \mathrm{We}$ investigated the effect of a prior histamine challenge on bronchodilatation with salbutamol after spontaneous recovery of $\mathrm{FEV}_{1}$ order to assess the feasibility of performing the two tests reliably on the same day. Although $\mathrm{FEV}_{1}$ after $400 \mu \mathrm{g}$ salbutamol was significantly diminished by a prior histamine challenge this was not the case after a further $100 \mu \mathrm{g}$ had been administered. When $800 \mu \mathrm{g}$ salbutamol was inhaled instead of $400 \mu \mathrm{g}$, no effect of a prior histamine challenge was observed. The increase in $\mathrm{FEV}_{1}$ due to $400 \mu \mathrm{g}$ salbutamol was smaller on the histamine challenge day than on the control day when related to pre-histamine $\mathrm{FEV}_{1}$, and that trend remained when related to post-histamine $\mathrm{FEV}_{1}$. After the further $100 \mu \mathrm{g}$ dose the change in $F E V_{1}$ as well as the level of $F E V_{1}$ appeared to be unaffected by the prior histamine challenge. Similarly, no influence of a prior histamine challenge on $\mathrm{FEV}_{1}$ or change in $\mathrm{FEV}_{1}$ was observed after inhalation of $800 \mu \mathrm{g}$ salbutamol.

Airways obstruction caused by histamine is a result of a complex process in which airway smooth muscle shortening and oedema ${ }^{15-17}$ of the airway wall due to increased post-capillary venular leakage $^{18}$ are thought to be predominant. A thickened mucosa and submucosa and altered volume and properties of airway secretions may affect the availability of the $\beta_{2}$ agonist to the receptor, limiting or delaying the bronchodilator response. Both the time of administration of the $\beta_{2}$ agonist after challenge and the dose of $\beta_{2}$ agonist may therefore influence its response. Some effects of histamine can be antagonised by $\beta_{2}$ agonists, which relax smooth muscle cells and inhibit the release of mediators from mast cells ${ }^{19}$; there is no evidence that $\beta_{2}$ agonists reverse airway oedema, though they may prevent its development. ${ }^{20}$ The influence of $\beta_{2}$ agonists on microvascular leakage and oedema of the airway wall has been studied only in animals, with conflicting reports, the findings varying with the species studied. ${ }^{172122}$

Results from protocol 1 suggest that after a histamine challenge the same plateau of $F E V_{1}$ $\%$ predicted is reached as on the control day but it is reached more slowly; this may reflect problems of bronchodilator access to parts of the bronchial tree and subsequent indirect delivery through the bronchial circulation. ${ }^{23}$ It is also possible that residual effects of the previous histamine challenge antagonise the response to salbutamol. This could explain why the histamine challenge had no effect on the bronchodilator response when the dose of salbutamol was doubled in the experiments in protocol 2. This is compatible with the observation that incubation of human lung tissue with histamine concentrations greater than $10 \mu \mathrm{mol} / 1$ induces release of bronchoconstricting $\left(\mathrm{PGF}_{2 \alpha}\right)$ and bronchodilating prostaglandins (PGE) ${ }^{24-26}$; these in turn can stimulate mast cells to release bronchodilating and bronchoconstricting prostaglandins. ${ }^{25}$ Circulating levels of prostaglandins remain raised for over 35 minutes, ${ }^{25} 27$ corresponding with the time airway calibre remains diminished when asthmatic patients inhale these prostaglandins. ${ }^{28}$ Estimates, on the assumption of an average thickness of the pericellular fluid layer of 5-6 $\mu \mathrm{m}^{29}$ and calculated by a method analogous to that used for terbutaline ${ }^{30}$ suggest that those in vitro concentrations of histamine are similar to those used in our experiments. Hence mediators released during a histamine challenge may affect the recovery of $\mathrm{FEV}_{1}$, and may in part explain why more $\beta_{2}$ agonist is needed even after spontaneous recovery of $\mathrm{FEV}_{1}$ to obtain the same response as that seen without a prior histamine challenge. Because a maximal effect was obtained a dose higher than the one we used seems unnecessary. After inhalation of this dose of salbutamol we observed a transient tremor in most children, as occurs in adults, ${ }^{31}$ but no other side effects.

We conclude that in children with stable asthma the same level of bronchodilatation, as assessed by $\mathrm{FEV}_{1}$, can be achieved with a $\beta_{2}$ agonist, whether or not a prior histamine challenge has been performed. This was achieved with a single $800 \mu \mathrm{g}$ dose of salbutamol, administered 70 minutes after the histamine challenge, when $\mathrm{FEV}_{1}$ has spontaneously returned to baseline. Thus the two tests can be performed on the same day. 
We thank the participants and the laboratory personnel of the Juliana and Sophia Children's Hospitals for their contributions to this andy. The work was supported by a grant from Netherlands Health Research Promotion Programme (SGO).

1 Cockcroft DW, Killian DN, Mellon JJA, Hargreave FE. Bronchial reactivity to inhaled histamine: a method and clinical survey. Clin Allergy 1977;7:235-43.

2 van Essen-Zandvliet EEM, Kerrebijn KF. The effect of antiasthma drugs on bronchial hyperresponsiveness. Immunol Allergy Clin North Am 1990;10:483-501.

3 Connolly MJ, Stenton SC, Avery AJ, Walters EH, Hendrick DJ. Refractory period following bronchoconstriction provoked by histamine in asthmatic subjects. Thorax 1989;44:146-50.

4 Manning PJ, Jones GL, O'Byrne PM. Tachyphylaxis to inhaled histamine in asthmatic subjects. J Appl Physiol 1987;63:1572-7.

5 Beaven MA. Histamine. N Engl J Med 1976;294:30-6.

6 Neijens HJ, Hofkamp M, Degenhardt HJ, Kerrebijn KF. Bronchial responsiveness as a function of inhaled histamine and the methods of measurement. Bull Eur Physiopathol Respir 1982;18:427-38.

7 Cartier A, Malo JL, Bégin P, Sestier M, Martin RR. Timecourse of the bronchoconstriction induced by inhaled histamine and methacholine. J Appl Physiol 1983;54: 821-6.

8 Gerritsen J, Koëter GH, Akkerboom HJ, Knol K. Recovery

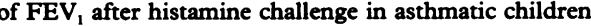
Clin Allergy 1987;17:119-26.

9 Malo JL, Gauthier R, Lemire I, Cartier A, Ghezzo $H$, Martin RR. Kinetics of the recovery of airway response caused by histamine. Am Rev Respir Dis 1985;132:848-52.

10 Quanjer PhH, ed. Standardized lung function testing. Bull Eur Physiopathol Respir 1983;19(suppl 5):45-51.

11 Zapletal A, Paul T, Samanek M. Reference values of static and dynamic lung function indices in children and adolescents [in Czech]. Cs Pediatr 1976;31:532-9.

12 Heimer D, Shim C, Williams MH Jr. The effect of sequential inhalations of metaproterenol aerosol in asthma. J Allergy Clin Immunol 1980;66:75-7.

13 Nieminen MM, Holli H, Lahdensuo A, Muittari A, Karvonen J. Aerosol deposition in automatic dosimeter nebulisation. Eur J Respir Dis 1987;71:145-52.

14 Eiser NM, Kerrebijn KF, Quanjer PhH. Guidelines for standardization of bronchial challenges with (nonspecific) bronchoconstricting agents. Bull Eur Physiopathol Respir 1983;19:495-514.

15 Long WM, Sprung CL, Fawal HE, Yerger LD, Eyre P, Abraham WM, et al. Effects of histamine on bronchial artery blood flow and bronchomotor tone. J Appl Physiol 1985;59:254-61.
16 Pietra GG, Szidon JP, Leventhal MM, Fishman AP. Histamine and interstitial pulmonary edema in the dog. Circ Res 1971;29:323-37.

17 Laitinen LA, Laitinen A, Widdicombe J. Effects of inflammatory and other mediators on airway vascular beds. $A m$ Rev Respir Dis 1987;135:67-70S.

18 Persson CGA, Erjefält IAL. Nonneural and neural regulation of plasma exsudation in airways. In: Kaliner MA Barnes PJ, eds. Neural control in health and disease. New York: Dekker, 1988:523-49.

19 Brown JK, Leff AR, Frey MJ, Reed BR, Lazarus SC, Shields $R$, et al. Characterization of tracheal mast cell reactions in vivo. Inhibition by a beta-adrenergic agonist. $A m R e v$ Respir Dis 1982;126:842-8.

20 Barnes PJ. Neural control of human airways in health and disease. State of the art. Am Rev Respir Dis 1986;134: 1289-314.

21 Persson CGA, Erjefalt I, Grega GJ, Svensjö E. The role of $\beta$ receptor agonists in the inhibition of pulmonary edema. Ann NY Acad Sci 1982;384:544-57.

22 Boschetto $P$, Roberts NM, Rogers DF, Barnes PJ. Effect of anti-asthma drugs on microvascular leakage in guinea pig airways. Am Rev Respir Dis 1989;139:416-21.

23 Deffebach ME, Charan NB, Lakshminarayan S, Butler J. The bronchial circulation. Small, but a vital attribute of the lung. Am Rev Respir Dis 1987;135:463-81.

24 Kaliner MA. Mast cell-derived mediators and bronchial asthma. In: Hargreave FE, ed. Airway reactivity. Mechanisms and clinical relevance. Proceedings of a symposium at McMaster University. Mississauga, Ontario: Astra Pharmaceuticals Canada, 1980:175-88.

25 Steel L, Platshon L, Kaliner M. Prostaglandin generation by human and guinea pig lung tissue: comparison of parenchymal and airway responses. J Allergy Clin Immunol 1979;64:287-93.

26 Blackwell GJ, Flower RJ, Nijkamp FP, Vane JR. Phospholipase $\mathrm{A} 2$ activity of guinea-pig isolated perfused lungs. $\mathrm{Br}$ J Pharmacol 1978;62:79-89.

27 Platshon $L$, Kaliner M. The effect of the immunologic release of histamine upon human lung cyclic nucleotide and prostaglandin generation. $J$ Clin Invest 1978;62:1113-21.

28 Mathé AA, Hedqvist $P$, Holmgren $P$, Svanborg $N$ Bronchial hyperreactivity to prostaglandin $F 2 \alpha$ and histamine in patients with asthma. BMJ 1973;i:193-6.

29 Sleigh MA, Blake JR, Liron N. The propulsion of mucus by cilia. State of the art. Am Rev Respir Dis 1988;137:726-41.

30 Newman SP. Therapeutic aerosols. In: Clark SW, Pavia D, eds. Aerosols and the lung in clinical and experimental aspects. London: Butterworths, 1984:197-224.

31 Vathenen AS, Britton JR, Ebden P, Cookson JB, Wharrad HJ, Tattersfield AE. High-dose inhaled albuterol in severe chronic airflow limitation. Am Rev Respir Dis 1988;138: $850-5$ 